\title{
Olhar muito além do vetor: uma análise a partir do discurso coletivo sobre uso de plantas no controle de vetores
}

\section{Janaina Vital de Albuquerque ${ }^{1}$, Solange Laurentino dos Santos $^{2}$ e Rejane Magalhães de Mendonça Pimentel ${ }^{3}$}

\author{
${ }^{1}$ Programa de Pós-Graduação em Desenvolvimento e Meio Ambiente. Universidade \\ Federal de Pernambuco. Av. Professor Moraes Rego, S/№. Cidade Universitária. \\ Recife-PE, Brasil (CEP 50740-465). E-mail: janainavital91@gmail.com. \\ ${ }^{2}$ Universidade Federal de Pernambuco. Centro de Ciências e Saúde. Departamento \\ de Medicina Social. Av. Professor Moraes Rego, S/№. Cidade Universitária. Recife- \\ PE, Brasil (CEP 50740-465). \\ ${ }^{3}$ Universidade Federal Rural de Pernambuco. Departamento Biologia-Botânica. \\ Rua Manuel de Medeiros, S/№. Dois Irmãos. Recife-PE, Brasil (CEP 52171-900).
}

Resumo. Diversos estudos comprovam a baixa efetividade das práticas de controle do vetor via aplicação de inseticidas em centros urbanizados. 0 uso de plantas no controle do Aedes aegypti tem se mostrado uma alternativa viável há várias décadas, entretanto, o desconhecimento dos indivíduos sobre a sua ação leva a rejeição desta medida. Sendo assim, objetiva-se identificar a partir do Discurso do Sujeito Coletivo (DSC) quais os conhecimentos, percepções e opiniões da população referentes ao uso de plantas no controle vetorial. 0 método do DSC foi utilizado segundo uma abordagem qualitativa. 0 local do estudo foi o Bairro de Mutirão, no Município de Serra Talhada, Estado de Pernambuco, Brasil, na coleta e a aplicação de entrevistas a 11 moradores selecionados em amostra por conveniência. Utilizouse da caminhada transversal a fim de evidenciar o micro e macro contextos do local e a técnica "bola de neve" na seleção dos participantes e aplicação das entrevistas. Considerando o macrocontexto, o município apresentou doenças relacionadas ao saneamento ambiental inadequado, envolvendo as infectoparasitárias relacionadas às condições precárias de vida, as quais continuam sendo relevantes no quadro de morbimortalidade da população. Percebeu-se, nos discursos, que muitas pessoas conhecem algum tipo de planta usada no controle de vetores. Os conhecimentos surgem de forma empírica através das falas transmitidas de geração em geração e de vivências do cotidiano. Existe uma perda das tradicionalidades nas ações de controle vetorial entre os moradores do alto sertão de Pernambuco, os quais adotam substâncias químicas ao invés de insumos vegetais, sem considerar os perigos e a contaminação do ambiente em que vivem. Por fim, considera-se importante o redirecionamento das ações e das políticas de educação em saúde que incorporem o uso
Recebido:

16/10/2019

Aceito:

30/12/2019

Publicado:

31/12/2019

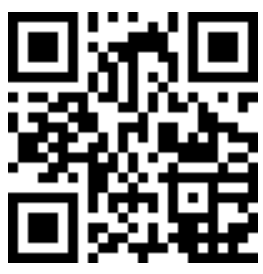

Acesso aberto

ORCID

D) $0000-0002-4843-3222$

Janaina Vital de

Albuquerque

(D) 0000-0002-6405-3959

Solange Laurentino

dos Santos

D 0000-0003-3211-7601

Rejane Magalhães de

Mendonça Pimentel 
de plantas para controle vetorial bem como investimentos em saneamento a fim de reduzir o risco de infestação vetorial transmissores de arboviroses.

Palavras-chave: Aedes aegypti; Semiárido pernambucano; Bioatividade de plantas; Percepção ambiental; Discurso coletivo.

Abstract. Looking beyond the vector: An analysis from the collective discourse on plant use in vector control. Several studies confirm the low effectiveness of vector control practices via insecticide applications in urbanized centers. The use of plants to control Aedes aegypti has been a viable alternative for several decades. However, the lack of knowledge about its action leads to the rejection of this measure. Thus, the objective is to identify from the Collective Subject Discourse (CSD), which are the knowledge, perceptions, and opinions of the population regarding the use of plants in vector control. The DSC method was used according to a qualitative approach. The study site was the neighborhood of Mutirão in the Municipality of Serra Talhada, State of Pernambuco, Brazil, to collect and conduct interviews with 11 residents selected for convenience. Cross-sectional walking was used to highlight the micro and macro contexts of the place and the snowball technique in the selection of participants and application of interviews. The municipality presented diseases related to inadequate environmental sanitation, involving infectious parasites related to poor living conditions, which remain relevant in the morbidity and mortality of the population. It was noticed in the speeches that many people know some plant used in vector control. Knowledge emerges empirically through the lines transmitted from generation to generation and everyday experiences. There is a loss of traditionality in vector control actions among the highlanders of Pernambuco, who adopt chemicals rather than plant inputs, without considering the dangers and contamination of the environment in which they live. Finally, it is considered essential to redirect health education actions and policies that incorporate the use of plants for vector control as well as investments in sanitation in order to reduce the risk of arboviral transmitter vector infestation.

Keywords: Aedes aegypti; Pernambuco semiarid; Plant bioactivity; Environmental perception; Collective speech.

\section{Introdução}

A atual situação epidemiológica do país, com a ocorrência da tríplice epidemia de arboviroses, dengue, febre de Chikungunya e síndrome congênita do zika vírus (SCZV), transmitidas pelo mosquito Aedes aegypti representam uma grave situação de descontrole epidemiológico, que não foi efetivamente previsto pelo sistema de vigilância em saúde pública.

As deficientes condições de saneamento ambiental existentes nos municípios brasileiros e, em particular na região nordeste do Brasil agravam esta situação epidemiológica de transmissão de arboviroses. Há que se considerar a 
desigualdade no uso da rede de abastecimento de água e os seus bens de serviços. Além disso, a localização das pessoas no território com pouca infraestrutura juntamente com o aumento da situação de pobreza estimulam a migração dos excluídos para os centros urbanos desde muitas décadas. Há uma supervalorização de certas áreas em detrimento de outras, causando o empobrecimento cumulativo da população (Santos, 1987).

A abordagem dos determinantes sociais identifica a demanda de distribuição da saúde como um importante indicador, não só em nível de igualdade e justiça social existente em uma sociedade, como também quanto ao funcionamento do Sistema de saúde que reduzem as iniquidades em saúde oferecendo um melhor desempenho e, assim, melhorando rapidamente as condições de saúde de grupos carentes, acabarão por oferecer um desempenho mais eficiente também para todos os estratos sociais (Carvalho, 2013).

Estudos como os de Londres (2011), Wutke et al. (2015) e Augusto et al. (2016a) comprovam a baixa efetividade das práticas usuais de controle vetorial via pulverização de inseticidas a Ultrabaixo Volume (UBV) (fumacê) em áreas urbanas.

A aplicação rotineira desses produtos possibilita a resistência do mosquito aos princípios ativos dos produtos aplicados; esse tipo de controle vetorial foi de suma importância no início de seu uso, quando as populações, tanto humana quanto do vetor, eram menores. Entretanto, a utilização destas práticas deveria ter sido interconectada às ações de prevenção, como o saneamento (Carneiro, 2015; ABRASCO, 2016; Augusto et al., 2016a). Além dos problemas ambientais e de resistência, estes produtos químicos podem causar problemas de pele e intoxicações, especialmente nos grupos mais susceptíveis, como crianças, gestantes e idosos (Wutke et al, 2015).
Augusto et al. (2016b) apontam que as áreas que têm interrupções no abastecimento de água estão associadas a um aumento do número de casos de dengue, devido aos sistemas inadequados de armazenamento de água potável; fatores como coleta de lixo e saneamento também são apontados como facilitadores na reprodução dos mosquitos.

\begin{abstract}
Esses problemas não podem ser corrigidos pelo vazamento de larvicidas na água e fornecer ou pulverizar casas com inseticidas, mas requerem capacitação e mobilização, bem como políticas públicas e apoio governamental para melhorar a saúde infra-estrutura e condições em bairros desfavorecidos (Augusto et al., 2016b).
\end{abstract}

Deste modo, o estudo objetivou caracterizar o micro e macrocontextos, onde as ações de controle do A. aegypti são desenvolvidas no sertão, cuja realidade representa o semiárido nordestino, avaliando a percepção dos sujeitos sociais sobre o controle vetorial com utilização de compostos derivados de plantas que possam ser úteis como ferramenta para uma gestão pública mais eficaz no controle de vetores. Como objetivos secundários objetivou-se analisar a percepção da comunidade no processo de transmissão de arboviroses, evidenciando os critérios norteadores (predominantes) na tomada de decisão, na utilização das medidas de controle realizadas pelo Município e propor novas práticas participativas junto com a comunidade, utilizando insumos vegetais para o controle do A. aegypti derivados de plantas cultivadas no semiárido.

\section{Metodologia}

0 estudo foi realizado no município de Serra Talhada, localizado na Região de Desenvolvimento do Sertão do Pajeú no Estado de Pernambuco (Figura 1). 0 bioma predominante é a Caatinga e o clima semiárido, apresen- 
tando um verão muito quente, com máximas de $31{ }^{\circ} \mathrm{C}$ e mínimas de $20^{\circ} \mathrm{C}$, caracterizando o período mais chuvoso.
0 índice pluviométrico oscila em torno de $686 \mathrm{~mm}^{-1} \cdot$ ano $^{-1}$ (Climate-Data.org, 2016).

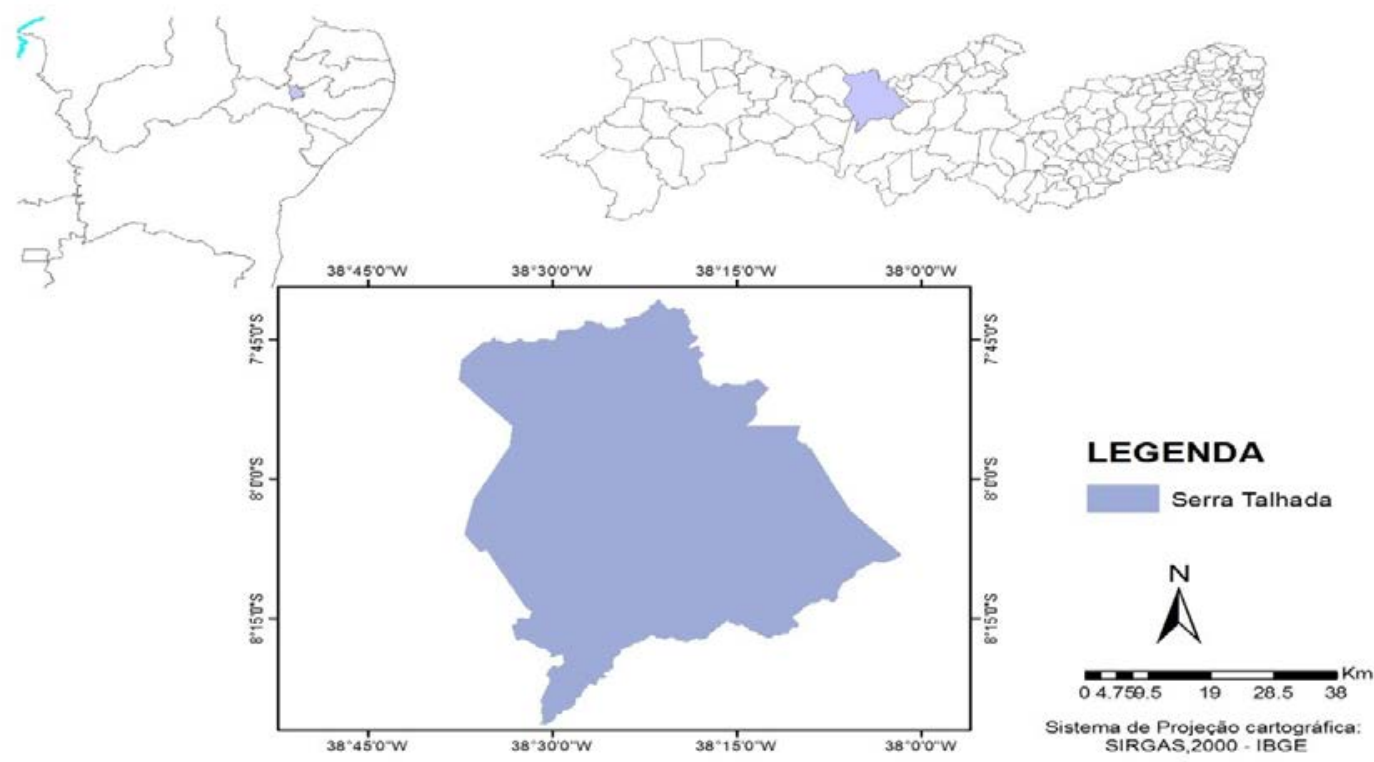

Figura 1. Mapa da região Nordeste do Brasil, com detalhe para o Estado de Pernambuco e o Município de Serra Talhada.

A área do estudo foi analisada nos anos de 2016 e 2017. O primeiro nível refere-se ao município de Serra Talhada e o segundo nível ao bairro de Mutirão, selecionado para o estudo (Figura 2).

o Bairro do Mutirão está localizado na região norte do município de Serra Talhada, possui 3.736 habitantes, com 946 imóveis residenciais e 18 quarteirões, destes, quatro apresentam alto risco de infestação do $A$. aegypti.

0 estudo foi realizado durante 12 meses, iniciando em janeiro de 2017 e sendo concluído em janeiro de 2018. A etapa de campo ocorreu nos meses de maio, agosto e outubro de 2017, com reconhecimento do local de estudo, coleta de dados primários, entrevistas e visualização do macro e micro contexto.

A etapa desenvolvida com os moradores iniciou-se com a utilização do método Bola de Neve (Goodman, 1961), onde o primeiro participante foi o morador com maior tempo de permanência no bairro e maior conhecimento sobre plantas, que indicava o próximo participante das entrevistas e assim sucessivamente.

A seleção do primeiro participante foi realizada por ocasião do contato inicial junto à comunidade, posteriormente foram obtidos os nomes de moradores que representariam a comunidade considerando o tempo de moradia, sociabilização com os demais moradores e conhecimentos populares locais na temática abordada no estudo. Em votação, por unanimidade, a moradora A foi escolhida pelos moradores, sendo a primeira entrevistada, dando início à aplicação do método Bola de Neve, até um total de 11 entrevistados. 




Figura 2. Setores censitários do micro contexto do estudo, Bairro Mutirão, em Serra Talhada/PE. Fonte: Secretaria de Saúde de Serra Talhada-PE (2017)..

Essa técnica desse caracteriza por enfatizar a fala dos sujeitos com maior visibilidade na população (Albuquerque, 2009), fato considerado no estudo como positivo, por serem formadores de opiniões.

$\mathrm{Na}$ caracterização do contexto foram consultados bancos de dados secundários de diferentes fontes, como o Instituto Brasileiro de Geografia e Estatística (IBGE, 2010), Planos e Relatórios de Secretarias Municipais, leis e portarias e atas de reuniões. Na caracterização do microcontexto utilizou-se, como fonte de dados primários, a técnica da "caminhada transversal", onde o pesquisador percorre a área de estudo acompanhado por um ou mais moradores da comunidade, visando abranger todo o território selecionado para o estudo (Souza e Dias, 2009). Essa experiência possibilitou visualizar a condição de vulnerabilidade socioambiental do bairro estudado, adicionando o registro fotográfico da área.

A seleção do participante para a caminhada transversal usou como critérios o tempo de residência, o conhecimento da história da comuni- dade, o domínio dos problemas e ser membro influente entre os moradores. Participaram da caminhada duas pessoas da comunidade.

$\mathrm{Na}$ etapa de avaliação da percepção dos sujeitos sociais sobre o controle do A. aegypti, seus determinantes e modos de controle, considerando o contexto da vida local, foi realizada a coleta de dados primários, utilizando as entrevistas com a comunidade. Foram realizadas entrevistas individuais e semiestruturadas. As entrevistas foram gravadas, não sendo estipulado um tempo mínimo, as falas foram livres de modo que, em alguns casos, tiveram duração de uma tarde inteira de conversas.

A metodologia de análise do DSC foi proposta por Lefèvre et al. (2000) e Lefèvre e Lefèvre $(2003,2006)$, sendo aplicada no campo dos estudos das áreas da saúde, como alternativa de enfrentamento dos problemas. 0 desafio que o DSC buscou responder foi o da expressão do pensamento ou opinião coletiva, respeitando sua dupla condição qualitativa e quantitativa.

0 resgate das opiniões coletivas que resulta em um conjunto de discursos 
coletivos é um processo complexo, subdividido em momentos e operações realizadas sobre o material coletado pela pesquisa. Trabalha com expressõeschave (ECh), ideias centrais (ICs) e ancoragens (ACs) para formar o DSC.

\begin{abstract}
Expressões-chave são trechos selecionados dos depoimentos, que melhor descrevem seu conteúdo. Ideias centrais são ideias sintéticas que descrevem os sentidos presentes nos depoimentos de cada resposta e também no conjunto de respostas de diferentes indivíduos que representam sentido semelhante ou complementar. Ancoragem são fórmulas sintéticas que descrevem não os sentidos, mas as ideologias, os valores, as crenças, presentes no material verbal das respostas individuais ou das agrupadas, sob a forma de afirmações genéricas destinadas a enquadrar situações particulares (Nicolau et al., 2015).
\end{abstract}

Para avaliar as falas de todos os grupos utilizou-se o "QualiQuantSoft", uma ferramenta que permitiu construir o DSC de cada grupo entrevistado. Considerada uma proposta nova em pesquisa social (Nicolau et al., 2015), permite relacionar, estreitamente, as dimensões qualitativa e quantitativa, associando pensamentos, crenças, valores e representações das características objetivas dos sujeitos, tais como sexo, idade, grau de instrução e renda, permitindo obter amostras bem selecionadas e relativamente grandes de indivíduos.

Após as análises das entrevistas, os DSC foram construído com trechos literais das respostas individuais $\mathrm{e}$ sistematizado. As variáveis foram agrupadas da seguinte maneira: 1-Saúde pública e ambiental (sobre o morador e a moradia); 2- Vetores e fatores de risco (sobre as doenças causadas pelo $A$. aegypti); 3-Bioatividade em plantas e controle vetorial (sobre os insumos vegetais na saúde pública).

A partir da delimitação de todas as Expressões Chaves foram criados blocos temáticos para selecionar as ideias centrais provisórias de cada uma das respostas.

Em seguida foram elaboradas as temáticas e suas conexões com a ideia central e o DSC, sendo analisadas, em profundidade, por meio da técnica de análise de conteúdo (Bardin, 1977), norteada pelas etapas: 1) Pré-análise: fase de organização, indicadores que fundamentem a interpretação; 2) Exploração do material: codificação dos dados a partir das unidades de registro; e 3) Tratamento dos resultados e interpretação: categorização, que consiste na classificação dos elementos segundo suas semelhanças e por diferenciação, com posterior reagrupamento, em função de características comuns.

No final da categorização de todos os segmentos de discursos individuais das questões propostas no grupo focal foram obtidos os DSCs.

Os DSCs levaram em consideração: condições de moradia e serviços básicos e doença; conhecimento sobre doença, o vetor e atividades de prevenção e controle tanto individuais quanto governamentais; atitude de prevenção da doença e de controle do vetor e práticas no domicílio para prevenir criadouros e de cuidado com reservatórios de água; bioatividade em plantas que combatem o A. aegypti; plantas medicinais no controle de vetores; uso de plantas no controle vetorial; conhecimentos e ancestralidades (de que maneira o participante aprendeu sobre esse uso).

0 projeto foi aprovado pelo Comitê de Ética em Pesquisa do Centro de Ciências da Saúde da Universidade Federal de Pernambuco (UFPE) e está registrado sob № 64637917.7 .0000 .5208 . Foi garantida a confidencialidade dos participantes. 


\section{Resultados e discussão}

O Município de Serra Talhada apresenta, atualmente, conforme dados do Levantamento de Índice Rápido para A. aegypti (LIRAa), de 2017, uma condição de alto risco (7.1), tendo apresentado, nos últimos anos, registro de surtos epidêmicos por arboviroses.

De acordo com dados do Núcleo de Vigilância em Saúde do Município de Serra Talhada, no ano de 2016, foram notificados 510 casos de dengue, sendo confirmados 167 casos, 296 casos descartados e 44 casos permanecidos em investigação. Em relação à chikungunya, foram notificados 104 casos, destes, 79 foram confirmados. Outra preocupação são os casos de microcefalia, pois sete casos foram notificados e três confirmados. Não foram notificados casos de ocorrência de Zika vírus no município, até o momento, devido à falta dos testes.

As fragilidades das infestações podem estar relacionadas às Políticas Públicas, entre elas estão a coleta seletiva de resíduos e a destinação irregular de esgoto e lixo doméstico, produzido diariamente no município e coletado de forma inadequada ou insuficiente (Lutinski, 2013). Esse fator contribui para elevar a quantidade dos potenciais criadouros, pois, na maioria das vezes, o lixo não coletado é depositado de forma inadequada em áreas públicas ou terrenos baldios proporcionando 0 desenvolvimento desses insetos (Pignatti, 2002).

Segundo o Núcleo Municipal de Vigilância em Saúde (2016), o primeiro LIRAa registrou um Índice de Infestação Predial de 33,7\%, sendo considerada uma situação de alto risco. 0 depósito predominante foi o A2 (pneus e depósitos de armazenamento de água).

o núcleo de coordenação da aplicação domiciliar relata a dificuldade de aplicação domiciliar e peridomiciliar.
Outro fator que deve ser levado em consideração nos programas de ação e controle do $A$. aegypti é a retirada de determinados compostos não mais utilizados dos acervos das Secretarias Municipais.

A ABRASCO (2016) analisou fatores que influenciam no aumento de número de casos das arboviroses, aspectos como:

Local de moradia, urbanização
precária, saneamento ambiental
inadequado com provimento à água
de forma intermitente, fato que leva
essas populações ao armazenamento
domiciliar inseguro de água,
condição muito favorável para a
reprodução do A. aegypti,
constituindo-se em "criadouros" que
não deveriam existir, e que são
passíveis de eliminação mecânica,
pela inadequada proteção dos
reservatórios destinados ao consumo
humano (ABRASCO, 2016).

Para o discurso foram convidados 11 moradores do bairro Mutirão, utilizando a técnica Bola de Neve para a extração das ideias centrais e dos respectivos discursos coletivos (Tabela 1), destes, quatro possuem nível médio completo, três possuem nível médio incompleto, três possuem fundamental incompleto e uma superior incompleto. A média de idade foi de 39 anos, estando a maioria na faixa etária entre 31 e 50 anos $(53,8 \%)$; mais de dois terços são do sexo feminino $(75,3 \%)$.

Avaliando os discursos dos moradores, foram considerados os eixos: 1- Saúde pública e ambiental - Gestão pública; Lixo: descarte e armazenamento; 2- Vetores e fatores de risco (sobre as doenças causadas pelo A. aegypti); Arboviroses transmitidas pelo A. aegypti; Doenças: Sintomas, curas e remédios; Ações de controle vetorial; 3Bioatividade em plantas e controle vetorial (Sobre os insumos vegetais na saúde pública); Uso de plantas para controle de mosquitos; Tradicionalidades. 
Tabela 1. Ideias centrais e perguntas norteadoras dos discursos.

\begin{tabular}{|l|l|}
\hline \multicolumn{1}{|c|}{ Perguntas norteadoras } & \multicolumn{1}{c|}{ Ideias centrais } \\
\hline $\begin{array}{l}\text { Como é feito o armazenamento e abastecimento de } \\
\text { água na sua casa? }\end{array}$ & $\begin{array}{l}\text { Ideia central I - A água vem da torneira e } \\
\text { guardamos nos tanques. }\end{array}$ \\
\hline $\begin{array}{l}\text { Quais os problemas vinculados ao saneamento } \\
\text { ambiental do seu bairro? }\end{array}$ & $\begin{array}{l}\text { Ideia central I - Falta de cuidado com o } \\
\text { ambiente. Presença de vetores devido ao lixo } \\
\text { e esgoto. }\end{array}$ \\
\hline $\begin{array}{l}\text { Conhece alguém que tenha sofrido algum efeito na } \\
\text { saúde com produtos químicos usados no seu } \\
\text { município? Se sim, o que ocorreu? Na sua opinão, } \\
\text { esses produtos químicos fazem algum mal à saúde? }\end{array}$ & $\begin{array}{l}\text { Ideia central I - Alergias e dores devido a } \\
\text { inalaço do fumacê. } \\
\text { Ideia central II - Se mata o mosquito pode } \\
\text { nos fazer mal. }\end{array}$ \\
$\begin{array}{l}\text { O governo faz alguma coisa para controlar o } \\
\text { mosquito? Se sim, quais são os esforços no seu } \\
\text { município? }\end{array}$ & $\begin{array}{l}\text { Ideia central I - Eles sempre passam com o } \\
\text { carro da fumaça, e campanhas de retirada do } \\
\text { lixo na rua. } \\
\text { Ideia central II - Aplicação de produtos } \\
\text { químicos pelos agentes de endemias. }\end{array}$ \\
\hline $\begin{array}{l}\text { Você acha que a Dengue, Febre Chikungunya e Zika } \\
\text { é um problema na sua comunidade? Qual acha pior } \\
\text { e por quê? }\end{array}$ & $\begin{array}{l}\text { Ideia central I - A Dengue é ruim, mas a } \\
\text { Chikungunya é pior, dói muito. }\end{array}$ \\
\hline $\begin{array}{l}\text { Conhece alguma planta que mate insetos, que seja } \\
\text { repelente ou que ajude contra os mosquitos? } \\
\text { Quais? Qual a parte usada dessa planta? }\end{array}$ & $\begin{array}{l}\text { Ideia central I - Conhecimentos passado por } \\
\text { familiares ou amigos. } \\
\text { Ideia central II - Usava, mas não funciona } \\
\text { mais, os mosquitos estão mais fortes. }\end{array}$ \\
\hline $\begin{array}{l}\text { Você usaria essa planta como controle dos } \\
\text { mosquitos? Por quê? Usa algum tipo de repelente } \\
\text { comprado? Quais? o que faria você usar o } \\
\text { repelente natural? }\end{array}$ & $\begin{array}{l}\text { Ideia central I - Sim, principalmente por ser } \\
\text { natural e não nos fazer mal. } \\
\text { Ideia central II - O ruim é que temos de fazer, } \\
\text { se já vendesse pronto só para aplicar seria } \\
\text { melhor ou se ele matasse mais. }\end{array}$ \\
\hline
\end{tabular}

Em relação à IC encontrada no DSC 1, a qual relata os cuidados com o ambiente e saúde pública, encontra-se os aspectos sobre o morador e sua moradia, além das ações relativas à gestão pública, formas de armazenamento de água e descarte e armazenamento de lixo.

Com relação à moradia, a maioria dos entrevistados moram no bairro há mais de 12 anos, o que confere uma maior experiência com relação às vivências locais. Considerando o número de moradores por residência, foi determinada uma média de quatro moradores por moradia, sendo todas elas de alvenaria. Nenhuma das residências visitadas possuíam telas ou algum tipo de proteção para que os mosquitos não entrassem.

Ao investigar os serviços básicos, foi avaliado o eixo 1 (Saúde pública e ambiental-Gestão pública; Lixo: descarte e armazenamento), considerando o suprimento e armazenamento de água. Observou-se que os moradores seguem a mesma conduta com no armazenamento de água devido a falta de água encanada.

Considerando como foco a pergunta que avalia o armazenamento e abastecimento de água nas casas vemos como DSC:

A água vem da torneira e guardamos nos tanques. Dependendo do tempo demora até mais de meio mês, já passamos mais de 10 dias sem água aqui. Mas agora está sempre vindo toda semana [...]. Passa todo dia não, tem vezes que passa mais de 5 dias e quando não tem eu uso a água do tanque, a água do balde é para beber [...]. Acho que todo mundo aqui armazena água, não tem como você viver aqui sem juntar água não. Se não você fica sem água. Já tivemos de 
nos juntar para ir na prefeitura porque estávamos sem água por muito tempo e comprar água é caro demais [...]. A água que bebe vem do açude também, vem pela torneira e guardo no tonel, e para tudo a diferença é só o vasilhame (DSC).

Quando questionado sobre as finalidades para a água armazenada identificamos que o sertanejo ainda utiliza métodos antigos, os quais são transmitidos de geração em geração. 0 conhecimento popular admite que a filtração da água em potes de barro mantém a água possível para consumo, além de deixa-la sempre fresca.

Outro ponto que merece destaque é a forma com que esses recipientes de armazenamento de água são limpos. Observou-se que os Agentes de Endemias locais pedem para que limpem menos os reservatórios que recebem os larvicidas para manter os princípios ativos atuando na água por um período de tempo mais longo.

Para tudo, tudo mesmo. Fazer comida, tomar banho, arrumar a casa e lavar prato. Quando chega agua todo mundo corre para lavar as roupas [...]. A água de beber colocamos separado para não sujar, é de barro a jarra, a água sempre fica bem fresquinha. Tenho bem uns 5 toneis de água lá fora. Cada um para uma coisa, mas quando acaba um eu uso do outro. Não tem jeito né minha filha [...]. É que eles botam remédio né, e eles falam que é só para lavar de vez em quando [...]. 0 agente fala para não limparmos sempre para não tirar o remédio que eles colocam (DSC).

Avaliando os serviços de coleta de lixo e serviços básicos no manejo dos resíduos sólidos, constatamos que o recolhimento do lixo era realizado três vezes na semana, sendo depositado em um local específico na rua para a coleta.

Com relação ao esgotamento sanitário, os moradores se mostraram insatisfeitos, principalmente no que diz respeito à obra inacabada de saneamento do bairro; comentam sobre os riscos promovidos pelas canaletas abertas e o descaso que sentem com relação à demanda de resíduos que permanecem ao longo da vala.

Quando questionados sobre os problemas vinculados ao saneamento ambiental precário na região e como isso pode gerar novas doenças, incluindo as arboviroses com a Dengue, Febre Chikungunya e Zika, nota-se que, mesmo com conhecimentos empíricos enraizados, como o mito de que o $A$. aegyptii só se reproduz em águas limpas e paradas, os moradores conseguem associar outras comorbidades a esse problema ambiental.

Não dizem que eles só podem viver em água limpa? Eu acho que se o danado gosta de água limpa e não damos mais agua limpa para ele, ele vai para a suja [...]. Não é isso que falam das coisas que eles estão mais fortes e com essas doenças todas que não tinham hoje pode ser que seja sim culpa do esgoto que deixou ele mais forte [...]. 0 esgoto a céu aberto tem água parada que acumula o mosquito da Dengue já que ninguém mexe no esgoto mesmo [...]. As outras doenças são tudo de um mosquito só então é tudo a mesma coisa (DSC).

0 eixo 2 (Vetores e fatores de risco) considerou as doenças causadas pelo A. aegypti; Doenças: Sintomas, curas e remédios; Ações de controle vetorial. Avaliando os efeitos na saúde promovidos por produtos químicos usados no controle da Dengue, e se esses produtos químicos fazem algum mal à saúde, constatou-se a existência de uma série de alergias e complicações.

Minha filha e eu ficamos com alergia do fumacê, por isso quando eles passam aqui pedindo para abrirmos as portas e as janelas para a fumaça entrar nos já vamos para casa da minha irmã. Minha filha é quem sofre mais, ela teve vômitos e o corpo dela 
fica todo vermelho, ficou com febre e o olho dela ficou vermelho. Ela fica assim por quase três dias aí vem novamente esse aperreio. Eu só fico com dor de cabeça e meu olho vermelho. Corro logo para tomar banho e deixo a casa toda fechada, mas mesmo assim fico com dor de cabeça. Eu fiquei com dor de barriga por mais de uma semana [...]. 0 menino disse que eu poderia beber a agua depois de duas horas eu tomei com mais de 3 horas e ainda fiquei morrendo de dor. Achei que ele colocou uma quantidade muito grande para o meu pote. Geralmente ele bota essa mesma quantidade na minha caixa, mas ela é enorme e meu tonel e bem pequeno (DSC).

A literatura relata que criações de animais domésticos e populações humanas são afetados pela ingestão de plantas e alimentos contaminados por agrotóxicos, além do impacto em comunidades e ecossistemas próximos às áreas de plantações e pastos, onde estes produtos são utilizados (Gomes, 2014).

Dessa maneira, além do impacto sobre uma população específica de animais ou plantas, a dispersão de agrotóxicos no ambiente pode causar um desequilíbrio ecológico relativo à interação natural de duas ou mais espécies.

Avaliando o eixo 2, Vetores e fatores de risco, quando questionados sobre o uso de produtos químicos, e como isso influi no cotidiano, foram registrados diferentes relatos:

Tenho um monte, no tanque eu tenho meus peixes, em casa eu tenho vários passarinhos, todos daqui mesmo [...]. É bom que a senhora tenha perguntado sobre isso. Um dia o menino lá da saúde foi lá em casa e colocou o pozinho no meu tanque de peixe mesmo eu tendo dito que os peixes estavam lá, ele me disse que não ia acontecer nada com eles, só que eles morreram[...]. E outro dia foi meu passarinho. Morreu mesmo com aquela fumaceira. Agora eu nem crio mais peixe e fico pensando que se eles morreram eu posso morrer também (DSC).

$\begin{array}{rlr}\text { Mesmo } & \text { sabendo das } \\ \text { problemáticas } & \text { geradas pelo uso }\end{array}$ continuado de agrotóxicos no controle vetorial, no Brasil, mais exatamente no Nordeste brasileiro, onde a população sofre com doenças crônicas, particularmente devido a escassez de água, a população ainda continua a consumir a água tratada com estes pesticidas, para o controle vetorial (ABRASCO, 2016).

Todos os inseticidas podem causar a contaminação de alimentos e água, quando não diluído ou aplicado de forma correta. A substituição do inseticida e, consequentemente, seu solvente, resultam na morte de animais e plantas, manchas em janelas e pisos das casas, piscinas e pintura de veículos (Gomes, 2014).

Inúmeras foram as reclamações feitas por moradores ao Centro de Controle de Zoonoses, como a morte de alguns cães, pássaros, peixes e até mesmo de árvores frutíferas, mas quando retornada as ligações, e orientados sobre os procedimentos legais de fazer uma reclamação junto ao protocolo geral da prefeitura e providenciar exames que comprove a causa da morte, os moradores desistiam das denúncias sendo assim em nenhuma das vezes teve essa comprovação (Gomes, 2014).

Levando em consideração a pergunta norteadora relativa à ação do Governo e das políticas de controle de vetores, os discursos se mostraram otimistas.

Eles tentam, né?, passam com o carro do fumacê, com aqueles das costas e o pozinho, mas mesmo assim o povo vive com essas doenças [...]. Eu tenho lá minhas dúvidas que esse esgoto aí não tenha ovo do mosquito. Teve um dia que estava na praça e fui picado por um mosquito da Dengue e claro que ela veio de lá [...]. Eles sempre 
passam com o carro da fumaça. Coletaram os pneus da rua e teve umas campanhas de lixo na rua. Sempre recebemos o aviso antes. Eles vêm na sua casa, perguntam onde guardamos a água e colocam o pozinho [...]. Falam para beber a água apenas duas horas depois de colocado, mas se quisermos esperar mais tempo é melhor [...]. Eles passam na casa de todos [...]. O nome do produto eu não sei, mas sei que eles matam as larvas e os ovos [...]. Depende da época do ano. Um rapaz passa de casa em casa pedindo para abrirmos as portas e janelas da casa para a fumaça entrar e matar os mosquitos que estão dentro da nossa casa. Não adianta ele só passar na rua e os de casa ficarem vivos [...]. Eles passam com o carro e ou com umas mochilas cheias do remédio e aplicam dentro de casa, parece as bombas de veneno do roçado (DSC).

Os tratamentos espaciais a Ultra Baixo Volume (UBV) geram muitas controvérsias, pois inúmeras são as vantagens e desvantagens desta metodologia de tratamento. Em primeiro lugar, sua utilização é apenas uma das atividades realizadas visando o controle do vetor, com a principal finalidade de interromper a propagação da doença, impactando, principalmente, o índice de infestação do mosquito adulto, as atividades de remoção de criadouros e a sensibilização da população, quanto a manter seus quintais livres de condições que favoreçam a proliferação dos mosquitos,essenciais para o controle do vetor (Ministério da Saúde, 2014).

Levando em consideração os problemas decorrentes das arboviroses foi perguntado quais delas eram o real problema ou pior condição quanto ao quesito relativo à infestação e sintomas. Analisando o discurso vimos que:

\footnotetext{
Sim, tem muita gente que eu conheço que sofreu muito com a Chikungunya, meu amigo mesmo agora nem anda direito e nem vai mais para o roçado que ele tinha de
}

macaxeira. Está complicado muita gente também foi demitida porque passaram muito tempo sem ir ao trabalho [...]. Eu mesmo fui lá com o corpo todo vermelho e dor demais e a mulher disse que era Chikungunya, voltei para casa nem conseguia abrir os olhos. Ainda sinto dor e já tem mais de um ano, mas tem gente que está até andando de cadeira de rodas [...]. A Dengue e ruim, mas a Chikungunya e pior, dói muito. Eu estou tentando pegar aposentadoria por invalides. Eu trabalho no roçado da família, mas não está sendo fácil. Tem dias que eu nem consigo fechar o punho para pegar na inchada, quem dirá rastelar. Antes eu carregava uma arroba de cará nas costas, hoje eu não consigo mais [...]. Tô tentando ajuda com um advogado que viu minha situação e está levando o processo de aposentadoria para frente. Eu tenho sorte porque guardei o papel lá do médico me dando atestado e dizendo que tinha Chikungunya [...]. Aqui quase todos ou tiveram a Dengue ou a Chikungunya, eu acho que nem mesmo eles sabem o que tiveram, tem gente que sabemos na hora que foi Chikungunya, a pessoa chega ficou escalpelada. A Zica não chegou aqui espero que não chegue (DSC).

Analisando o eixo 3 (Bioatividade em plantas e controle vetorial, os insumos vegetais na saúde pública) percebeu-se que muitos conhecem algum tipo de planta usada no controle de vetores. Os conhecimentos surgem de forma empírica, a partir dos conhecimentos passados de geração em geração e de vivências do cotidiano.

Quando questionados sobre o conhecimento sobre alguma planta que mate insetos, que seja repelente ou que ajude contra os mosquitos, seus usos e como atua, obtivemos como discurso:

Nome da planta eu não sei, só sei que o boi come essa planta porque Mãe usava muito o coco do boi seco para espantar muriçoca. Ela só parou porque o vizinho achava o cheiro 
ruim, e nem tinha cheiro de bosta. Uso só quando eu lembro e quando estou sem dinheiro [...]. Citronela tem um monte de repelente que compro que tem citronela. Não gosto muito do cheiro, mas uso. Pelo menos tem cheiro de planta e não de Hipoglós [...]. Eu ainda uso, mas sempre que tem visita e ou eu vou sair passo os outros por causa do cheiro [...]. Cascas de laranja [...]. Eu vi na intermete e fiz, fiz também o de cravo no álcool. Acho o cheiro muito forte mas funciona só tira o cheiro do perfume todinho. Uso sim e uso o que eu fiz de cravo também. Uso esse spray e os para passar no corpo [...]. No sitio que eu trabalhei lá em Goiana eles queimavam eucalipto e passava ao redor da casa e nunca tinha mosquito dentro e a casa sempre fica com cheiro de limpa [...]. Eu usava a pitanga amassada funcionava muito. No sítio usávamos folhas de Umburana (DSC).

Não uso mais porque falaram que não adianta mais porque o mosquito está mais forte. 0 ruim é que temos de fazer, se já vendesse pronto só para aplicar seria melhor (DSC).

É necessário que ocorra um fortalecimento da educação ambiental, incorporando ações concretas de práticas de prevenção, provocando debates, palestras, simpósios, conferências, entre outros, permitindo que a população se sensibilize com a causa, levando a uma prevenção do problema.

A partir dos discursos é notável o conhecimento da população de inseticidas botânicos, cabe a iniciativa Pública bem como a população esse resgate e uso continuado de produtos ecologicamente viáveis, socioeconomicamente mais rentáveis para populações de base e cabível devido a seu uso e manutenção de baixo ou nenhum custo adicional.

\section{Conclusões}

0 uso de inseticidas químicos ainda é considerado a melhor forma de combate do mosquito $A$. aegypti, apesar de saber que seu uso causa resistência no animal.

Há precariedade no saneamento e as ações de educação são insuficientes; alguns componentes básicos, como saneamento do meio ambiente, ações de educação ambiental, comunicação e informação e combate direto do vetor, com foco perifocal, devem estar entrelaçados com os saberes da população para tornar mais eficaz a conscientização da população quanto às formas de combate do mosquito.

Recomendam-se ações de educação ambiental como uma forma mais eficiente de controle vetorial, permitindo a diminuição dos índices de infestação predial das taxas de incidência de doenças.

\section{Agradecimentos}

As autoras agradecem à Secretaria de Saúde de Serra Talhada, em especial ao Núcleo Municipal de Vigilância em Saúde, bem como a população do Bairro de Mutirão e ao Conselho Nacional de Desenvolvimento Científico e Tecnológico (CNPq) pela bolsa de mestrado concedida à primeira autora.

\section{Conflitos de interesse}

As autoras declaram não haver conflitos de interesses.

\section{Referências}

ABRASCO - Associação Brasileira de Saúde Coletiva. Nota técnica sobre microcefalia e doenças vetoriais relacionadas ao Aedes aegypti: os perigos das abordagens com larvicidas e nebulizações químicas - fumacê. 2016. Disponível em: <http://www.abrasco. org.br/site/noticias/institucional/notatecnica-sobre-microcefalia-edoencasvetoriais-relacionadas-ao-A.-aegypti-osperigos-das-abordagens-comlarvicidas-enebulizacoes-quimicas-fumace/15929/>. Acesso em: 21 out 2018. 
Albuquerque, E. M. Avaliação da técnica de amostragem "respondent-driven sampling" na estimação de prevalências de doenças transmissíveis em populações organizadas em redes complexas. Rio de Janeiro: Escola Nacional de Saúde Pública Sérgio Arouca, 2009. (Dissertação de mestrado).

Augusto, L. G. S.; Gurgel, A. M.; Costa, A. M.; Diderichsen, F.; Lacaz, F. A.; Parra-Henao, G.; Rigotto, R. M.; Nodari, R.; Santos, S. L. Aedes aegypti control in Brazil. The Lancet Infectious Disease, v. 387, n. 10023, p. 10521053, 2016a. https://doi.org/10.1016/ S0140-6736(16)00626-7

Augusto, L. G. S.; Santos, S. L.; Diderichsen, F. Review of the Aedes aegypti control strategy is needed: chemical warfare or tackling the social determination. WATERLAT GLOBACIT Research Network, v. 3, n. 9, p. 62-67, 2016b. Disponível em: <http://waterlat.org/WPapers/WPSATGSA3 9.pdf>. Acesso em: 24 jul. 2019.

Bardin, L. Análise de conteúdo. Lisboa: Edições 70, 1977.

Carneiro, F. F.; Augusto, L. G. S.; Rigotto, R. M.; Friedrich, K.; Búrigo, A. C. (Orgs.). Dossiê ABRASCO: um alerta sobre o impacto dos agrotóxicos na saúde. Rio de Janeiro: EPSJV, São Paulo: Expressão Popular, 2015. Disponível em: <https://www.abrasco. org.br/dossieagrotoxicos/wp-content/ uploads/2013/10/DossieAbrasco_2015_web. pdf $>$. Acesso em: 24 jul. 2019.

Carvalho, A. I. Determinantes sociais, econômicos e ambientais da saúde. In: Fundação Oswaldo Cruz. A saúde no Brasil em 2030: prospecção estratégica do sistema de saúde brasileiro: população e perfil sanitário. Rio de Janeiro: Fiocruz, IPEA, Ministério da Saúde, Secretaria de Assuntos Estratégicos da Presidência da República, 2013. v. 2. p. 19-38.

Climate-Data.org. Clima Serra Talhada: temperatura, tempo e dados climatológicos Serra Talhada. 2016. Disponível em: $<$ https://pt.climate-data.org/america-dosul/brasil/pernambuco/serra-talhada42488/>. Acesso em: 24 dez. 2019.

Gomes, W. Uso de inseticida (organofosforado) no combate à dengue e os possíveis danos à saúde pública na área urbana de Foz do Iguaçu-PR. Medianeira:
Universidade Federal do Paraná, 2014. (Monografia).

Goodman, L. A. Snowball sampling. Annals of Mathematical Statistics, v. 32, n. 1, p. 148170, 1961. https://doi.org/10.1214/aoms/ 1177705148

Hemingway, J.; Ranson, H. Insecticide resistance in insect vectors of human disease. Annual Review of Entomology, v. 45, p. 371-391. 2000. https://doi.org/10.1146/ annurev.ento.45.1.371

IBGE - Instituto Brasileiro de Geografia e Estatística, 2010. Disponível em: <http://www.ibge.gov.br/home/>. Acesso em: 01 jun. 2019.

Lefèvre, F.; Lefèvre, A. M. C. 0 discurso do sujeito coletivo: um novo enfoque em pesquisa qualitativa. Caxias do Sul: EDUCS, 2003.

Lefèvre, F.; Lefèvre, A. M. C.; Teixeira, J. J. V. 0 discurso do sujeito coletivo: uma nova abordagem metodológica em pesquisa qualitativa. Caxias do Sul: EDUCS, 2000.

Lefèvre, F.; Lefèvre, A. M. O sujeito coletivo que fala. Interface - Comunicação, Saúde, Educação, v. 10, n. 20, p. 517-524, 2006. https://doi.org/10.1590/S1414-32832006 000200017

Londres, F. Agrotóxicos no Brasil: um guia para ação em defesa da vida. 1. ed. Rio de Janeiro: AS-PTA, 2011.

Lutinski, J. A. Infestação pelo mosquito Aedes aegypti (Diptera: Culicidae) na Cidade de Chapecó-SC. Biotemas, v. 26, n. 2, p. 143-15, $2013 . \quad$ https://doi.org/10.5007/21757925.2013v26n2p143

Ministério da Saúde. Aplicação espacial de inseticidas. 2014. Disponível em: <http://www.saude.gov.br/saude-de-az/controle-de-vetores-inseticidas-elarvicidas/aplicacao-espacial-de-inseticidas>. Acesso em: 01 jun. 2019.

Nicolau, K. W.; Escalda, P. M. F.; Furlan, P. G. Método do discurso do sujeito coletivo e usabilidade dos softwares Qualiquantisoft e DSCsoft na pesquisa qualiquantitativa em saúde. Fronteiras: Journal of Social, Technological and Environmental Science, v. 4, n. 3, p. 87-101, 2015. https://doi.org/ 10.21664/2238-8869.2015v4i3.p87-101 
Pignatti, M. G. Políticas ambientais e saúde: as práticas sanitárias para o controle do dengue no ambiente urbano. Cuiabá: UFMT, Instituto de Saúde Coletiva, 2002.

Secretaria de Saúde de Serra Talhada. Núcleo Municipal de Vigilância em Saúde. Plano de enfrentamento das doenças transmitidas pelo Aedes aegypti. Serra Talhada: Núcleo Municipal de Vigilância em Saúde, 2017.

Souza, T. B. B.; Dias, J. P; Perfil epidemiológico da dengue no Município de Itabuna (BA), 2000-jun. 2009. Revista Baiana de Saúde Pública, v. 34, n. 3, p. 665-681, 2009. Disponível em: <http://files.bvs.br/ upload/S/0100-0233/2010/v34n3/ a1873.pdf>. Acesso em: 01 jun. 2019.

Wutke, E. B.; Ambrosano, E. J.; Calegari, A.; Wildner, L. P.; Miranda, M. A. C. Aedes aegypti: controle pelas crotalárias não tem comprovação científica. Campinas: Instituto Agronômico, 2015. (Documentos IAC 114). 